\title{
Dental Pulp Capping
}

National Cancer Institute

\section{Source}

National Cancer Institute. Dental Pulp Capping. NCI Thesaurus. Code C63715.

The application of a barrier substance to either the dentin or the dental pulp of a tooth which protects the tooth from contact with oral contaminants. This allows for recovery and restoration of the dental pulp. 